\title{
Long-Term (4-Year) Outcomes and Predictors of Adverse Cardiac Events After Sirolimus-Eluting Stent Implantation in Unprotected Left Main Coronary Artery
}

\author{
XiaoFan Wu, ${ }^{1} \mathrm{MD}$, YunDai Chen, ${ }^{2} \mathrm{MD}$, Takashi Kubo, ${ }^{3} \mathrm{MD}$, ChangJiang Ge, ${ }^{1} \mathrm{MD}$, Fang Ren, ${ }^{1} \mathrm{MD}$, \\ $\mathrm{Xi} \mathrm{Wu},{ }^{1} \mathrm{MD}$, WeiJun Chen, ${ }^{1} \mathrm{MD}$, Yuan Zhou, ${ }^{1} \mathrm{MD}$, Hong Liu, ${ }^{1} \mathrm{MD}$, \\ and Shuzheng Lv, ${ }^{1} \mathrm{MD}$
}

\begin{abstract}
SUMMARY
The long-term safety and efficiency of sirolimus-eluting stent (SES) treatment in unprotected left main coronary artery (ULMCA) have not yet been ascertained.

From 2003 to 2006, 126 consecutive patients with de novo lesions in ULMCA who underwent SES were retrospectively analyzed in a single center in China. During 4-year follow-up, major adverse cardiovascular event (MACE)-free survival was 74.6\%. Cardiac death occurred in $5(4.0 \%)$, and target lesion revascularization (TLR) and target vessel revascularization (TVR) occurred in $15(11.9 \%)$ and $24(19.0 \%)$ patients, respectively. One $(0.8 \%)$ experienced probable stent thrombosis while $1(0.8 \%)$ presented possible stent thrombosis. Impaired LVEF $(<40 \%)$ and high surgical risk (Euro score $>6$ ) were the independent predictors of MACEs.

PCI with SES for de novo lesions in ULMCA is feasible with a low procedural risk. However, SES was associated with a relatively higher rate of TLR and TVR. Impaired LVEF and high surgical risk were important predictors of MACEs. (Int Heart J 2010; 51: 377-382)
\end{abstract}

Key words: Angioplasty, Left main coronary artery stenosis, Sirolimus-eluting stents

$\mathrm{L}$ eft main stenosis occurs in $4 \%$ to $6 \%$ of all patients undergoing coronary angiography. ${ }^{1,2)}$ Preliminary trial results confirmed that implantation of a drug-eluting stent (DES) to treat unprotected left main coronary artery (ULMCA) disease is feasible and relatively safe in appropriately selected patients. ${ }^{3-9)}$ However, in-stent restenosis and the risk of late thrombosis limit the widespread application of DES, especially because of the potential risk of sudden death associated with ULMCA restenosis. The aim of the present study was to evaluate the long-term clinical outcomes and identify associated predictors for major adverse cardiac events (MACEs) in patients undergoing elective intervention with sirolimus-eluting stents (SES) for ULMCA lesions in a "real-world" setting at a single center in China.

\section{MethodS}

Study population: Between February 2003 and December 2006, 126 consecutive patients presenting with stable angina or acute coronary syndrome (ACS), and with a de novo $\leq 50 \%$
ULMCA stenosis who underwent elective PCI with SES were enrolled in this study. Patients presenting with ST-segment elevation myocardial infarction or cardiogenic shock were excluded. All patients provided written informed consent, and the local ethics committee approved the use of clinical data for this study.

The decision to perform PCI rather than CABG was dependent on either physician or patient preference. Thirty-nine (31\%) patients treated with PCI were considered high risk for CABG with a Euroscore $>6$ or Parsonnet score $>15^{10,11)}$

Procedural characteristics: All interventions were performed according to concurrent practice guidelines. ${ }^{12,13}$ Bifurcation lesions were treated using one of 4 stenting strategies at the discretion of the operator: Crossover, $\mathrm{T}$ stent, Culotte stent, or the Crush technique ${ }^{14,15)}$ Final kissing balloon dilation was mandatory in cases with suboptimal results at the branch ostium. The choice of a particular SES and antithrombotic agent utilized was made by the operator. Overall, 126 patients received SESs including Cypher (Johnson \& Johnson, Cordis, Miami Lakes, FL, USA), Firebird (Microport Co. Ltd., Shanghai, China), Partner (Lepu Medical Technology Co. Ltd., Beijing, China),

From the ${ }^{1}$ Department of Cardiology, Beijing Anzhen Hospital, Capital Medical University, ${ }^{2}$ Department of Cardiology, Chinese PLA General Hospital, Beijing, China, and ${ }^{3}$ Department of Cardiology, Wakayama Medical University, Wakayama, Japan.

YunDai Chen serves as a consultant to Bayer HealthCare and Pfizer Pharmaceuticals Limited, and has received research grant support from Sanofi-Aventis Corporation.

Shuzheng Lv serves as a consultant of Pfizer Pharmaceutical Limited and Sanofi-Aventis Corporation, and has received research grant support from Lepu Medical Technology.

This work was funded by the Beijing Municipal Science \& Technology Commission, China (No. D0906006000091)

Address for correspondence: Shuzheng Lv, MD, Department of Cardiology, Beijing Anzhen Hospital, Capital Medical University, No.2 Anzhen Road, Chaoyang District, Beijing 100029, P.R. China.

Received for publication May 10, 2010

Revised and accepted July 26, 2010 
and Excel (JW Medical Co. Ltd., Shandong, China). Cypher stent was available in sizes of 2.5-3.5 mm and in lengths of 8-33 mm; Firebird, Partner, and Excel stents were available in sizes of 2.5-4.0 mm and in lengths of 13-33 mm, 12-36 mm, and 14-28 mm, respectively. Firebird and Partner stents are similar to Cypher stents in terms of stent platform, durable polymer, and drug dose, and the Excel stent is coated with a biodegradable polymer. All of these 3 stents have been validated equally and effectively compared with Cypher stent, ${ }^{16-19)}$ and have been approved for clinical use in China by the State Food and Drug Administration.

All patients were prescribed aspirin plus clopidogrel (loading dose, $300 \mathrm{mg}$ or $600 \mathrm{mg}$ ) or ticlopidine (loading dose, $500 \mathrm{mg}$ ) before or during the coronary intervention. After discharge, aspirin was continued indefinitely (100 mg/day); clopidogrel (75 mg/day) or ticlopidine ( $250 \mathrm{mg} /$ day) was continued for at least 12 months. Since 2004 when available, adjunctive cilostazol (100-200 mg/day) for 6 months was administered to patients with maximal platelet aggregation $>50 \%$ with $5 \mu \mathrm{mol} /$ L ADP tested 2 days after the procedure, but before discharge.

Coronary angiographic analysis: Baseline, postprocedural, and follow-up coronary angiograms were digitally recorded and assessed off-line with an automated edge-detection system (Cardiovascular Analysis Software, Beijing Crealife Technology Co., Ltd, China) by 2 independent and experienced physicians unaware of the treatment allocation. Quantitative analysis was performed on the left main segment. The left main stenosis was classified as ostial (stenosis located within $3 \mathrm{~mm}$ of LMCA ostium), midshaft (in the medial part of LMCA having at least $3 \mathrm{~mm}$ of apparently nondiseased artery before bifurcation), and distal (stenosis involves the distal part of the LMCA and bifurcation/trifurcation with proximal left anterior descending, left circumflex, or ramus intermedius).

Study definitions and follow-up: Clinical, angiographic, procedural, and outcome data were collected. All outcomes of interest were confirmed by source documentation and were adjudicated by the Institutional Review Board (IRB) of Capital Medical University, Anzhen Hospital, Beijing. Clinical followup at clinic after PCI was performed at 1 month, 6 months, 1 year, and annually thereafter. Angiographic follow-up was scheduled between 8 and 12 months after revascularization or whenever clinically indicated. Assessed endpoints were death, myocardial infarction (MI), target lesion revascularization (TLR), target vessel revascularization (TVR), and MACEs (death, MI, and TVR).

ULMCA was defined as left main stenosis $\geq 50 \%$ and no bypass grafts to the left anterior descending artery or left circumflex artery. Revascularization was considered complete when all vessels $>1.5 \mathrm{~mm}$ in diameter with diameter stenosis $\leq 50 \%$ by visual estimation were treated. Procedural success was defined as left main revascularization with a $\leq 30 \%$ residual diameter stenosis by quantitative coronary angiography, without major procedural or postprocedural adverse events. Death was postprocedure death from any cause. Deaths that could not be classified were considered cardiac according to the Academic Research Consortium (ARC) definitions. ${ }^{20)} \mathrm{MI}$ (within 7 days after intervention) was defined as elevated serum creatine kinase-MB isoenzyme $\geq 3$ times the upper limit of normal, associated with chest pain lasting $>30$ minutes or with new evident electrocardiographic changes. Cardiac enzymes were not measured routinely unless there was a clinical suspicion of ischemia. Angiographic binary restenosis was defined as diameter stenosis $\geq 50 \%$. Target lesion revascularization was defined as any repeat PCI of the target lesion in the left main artery, including the bifurcation. The target lesion was defined as the treated segment in the left main segment from $5 \mathrm{~mm}$ proximal to the stent to $5 \mathrm{~mm}$ distal to the stent. TVR was defined as repeat revascularization of any segment of the target vessel including the entire treated major coronary vessel. A MACE was defined as the occurrence of death, nonfatal MI, or TVR. Stent thrombosis was classified as definite, probable, or possible according to the ARC criteria and as early (0 to 30 days), late ( 31 to 365 days), or very late (> 1 year) after the index PCI. ${ }^{16)}$ Major bleeding was defined as any intracranial bleeding, bleeding associated with the need for blood transfusion, or any other clinically relevant bleeding as judged by the investigator. All events were based on clinical diagnoses assigned by the attending physician and were centrally adjudicated by an independent group of clinicians. In the cumulative analysis of endpoints, events were counted only once, whichever occurred first.

Statistical analysis: Continuous variables are presented as the mean \pm SD or median ( $25 \%$ to $75 \%$ interquartile range) and were compared by the Student $t$-test or Mann-Whitney rank sum test, as appropriate. Categorical variables were compared by chi-square statistics or Fisher's exact test, as appropriate. $P$ values $<0.05$ were considered statistically significant. Survival curves were generated by the Kaplan-Meier method. Bivariate and multivariate analyses were performed to identify independent predictors of adverse events. Specifically, all variables significantly associated with the clinical event of interest on bivariate analyses $(P<0.10)$ were entered into subsequent models, multiple variable Cox proportional hazard analyses were then performed, with the enter method for all pertinent covariates. Results of multiple variable Cox analyses are reported as hazard ratios (HR) together with the associated exact 95\% confidence intervals (CI) and $P$ values. Statistical analysis was performed using SPSS 15.0 software (SPSS Inc, Chicago, IL).

\section{RESULTS}

Clinical characteristics: The baseline clinical characteristics are shown in Table I. The mean age of the patients was $61.5 \pm$ 10.7 years (range, 36 to 84 ); $75.4 \%$ were male, $27 \%$ had diabetes mellitus, and ACSs were present in $67.5 \%$ of the overall cohort. More than $20 \%$ of the patients were considered to be at high surgical risk on the basis of a Euroscore value of $\geq 6$ (29.4\%) and a Parsonnet score of $\geq 15$ (23\%). Poor ventricular function with a left ventricular ejection fraction (LVEF) $\leq 40 \%$ was present in $12.7 \%$ of the patients.

Angiographic and procedural characteristics: The main angiographic and procedural characteristics are shown in Table II. In brief, $67.9 \%$ had a bifurcation/trifurcation lesion, and $35.1 \%$ presented with concomitant 3-vessel disease. Procedural success was obtained in 124 patients $(98.4 \%)$. Eighty (63.5\%) patients received PCI treatment of lesions in vessels other than the left main (47 RCA, 36 LAD, and 36 LCX), and 13 (10.3\%) patients were treated in left main plus 3-vessel.

Follow-up and outcomes: One hundred and twenty-five patients $(99.2 \%)$ received complete clinical follow-up for 3.8 
Table I. Baseline Clinical Characteristics

\begin{tabular}{|c|c|}
\hline Men, $n(\%)$ & $95(75.4)$ \\
\hline Age, years & $61.5 \pm 10.7$ \\
\hline Diabetes mellitus, $n(\%)$ & $34(27.0)$ \\
\hline Hypertension, $n(\%)$ & $81(64.3)$ \\
\hline Hypercholesterolemia, $n(\%)$ & $39(31.0)$ \\
\hline Previous myocardial infarction, $n(\%)$ & $14(11.1)$ \\
\hline Previous stroke, $n(\%)$ & $10(7.9)$ \\
\hline Peripheral vascular disease, $n(\%)$ & $4(3.2)$ \\
\hline Current smoker, $n(\%)$ & $51(40.5)$ \\
\hline Renal failure, ${ }^{*} n(\%)$ & $3(2.4)$ \\
\hline LVEF, \% & $60.1 \pm 11.9$ \\
\hline $\mathrm{LVEF} \leq 40 \%, n(\%)$ & $16(12.7)$ \\
\hline Euroscore & $4.2 \pm 2.7$ \\
\hline Eurocore $>6, n(\%)$ & $37(29.4)$ \\
\hline Parsonnet score & $8.6 \pm 6.3$ \\
\hline Parsonnet score $>15, n(\%)$ & $29(23.0)$ \\
\hline \multicolumn{2}{|l|}{ Clinical presentation, $n(\%)$} \\
\hline Stable angina & $41(32.5)$ \\
\hline Unstable angina & $78(61.9)$ \\
\hline NSTEMI & $7(5.6)$ \\
\hline Time from admission to procedure, days & $3.5 \pm 3.8$ \\
\hline Postprocedural hospital stay, days & $4.0 \pm 4.9$ \\
\hline Hospitalization, days & $7.5 \pm 6.3$ \\
\hline \multicolumn{2}{|l|}{ Medical therapy at 1 year, $n(\%)$} \\
\hline Aspirin & $117(92.9)$ \\
\hline Thienopyridine & $115(91.3)$ \\
\hline Beta-blocker & $105(83.3)$ \\
\hline Cilotazol $^{\dagger}$ & $32(25.4)$ \\
\hline Statin & $109(86.5)$ \\
\hline $\begin{array}{l}\text { ACE inhibitor or angiotensin II-receptor } \\
\text { antagonist }\end{array}$ & $86(68.3)$ \\
\hline
\end{tabular}

Values are expressed as the mean $\pm \mathrm{SD}$ or $n(\%)$. *Serum creatinine concentration of $\geq 2 \mathrm{mg} / \mathrm{dL}$; ${ }^{\dagger}$ Cilostazol administered for at least 6 months. ACE indicates angiotensin-converting enzyme; $\mathrm{Cr}$, creatinine; LVEF, left ventricular ejection fraction; and NSTEMI, non ST-segment elevation myocardial infarction.

$(3.2,4.5)$ years. Overall, during the median of 3.8-years follow-up, $5(4.0 \%)$ cardiac deaths occurred according to the ARC criteria: 2 died of MI, $1(0.8 \%)$ presenting with probable acute stent thrombosis died within 1 day after the procedure, but without angiographic or pathologic confirmation, one who suffered possible late stent thrombosis discontinued clopidogrel and died suddenly 8 months after the procedure, and one died suddenly. Six (4.8\%) had an MI. TLR and TVR were necessary in $15(11.9 \%)$ and $24(19.0 \%)$ patients, respectively. Overall, a MACE occurred in 32 (25.4\%) patients after SES. No major bleeding complications occurred during hospitalization or follow-up. The MACE-free survival rates during follow-up are summarized in Table III and the Figure. Of note, the great majority of events occurred within 1 year, whereas the cumulative event rate tended to stabilize over time.

Following the procedure, an ACS occurred in 31 patients (24.8\%). Angiographic follow-up was performed in 73 (57.9\%) patients at $10.4(6.4,15.5)$ months. Ischemic-driven angiographic follow-up was performed in 26 patients $(35.6 \%, 20.6 \%$ in overall cohort) while scheduled angiographic follow-up was performed in 47 patients $(64.4 \%, 37.3 \%$ in overall cohort). Among patients with angiographic follow-up, ischemic-driven TLR occurred in 14 patients and asymptomatic TLR occurred in 1 patient $(53.8 \%$ versus $2.1 \%, P<0.001)$. Nine TLR occurred in patients with double stents at the left main segment
Table II. Angiographic and Procedural Characteristics

\begin{tabular}{|c|c|}
\hline \multicolumn{2}{|l|}{ Lesion location, $n(\%)$} \\
\hline Ostium/midshaft & $42(33.3)$ \\
\hline Distal bifurcation/trifurcation & $84(67.9)$ \\
\hline \multicolumn{2}{|l|}{ Extent of disease vessel, $n(\%)$} \\
\hline Left main only & $11(8.7)$ \\
\hline Left main plus single-vessel disease & $23(18.3)$ \\
\hline Left main plus double-vessel disease & $48(38.1)$ \\
\hline Left main plus triple-vessel disease & $44(34.9)$ \\
\hline RCA dominant, $n(\%)$ & $95(75.4)$ \\
\hline Right coronary artery disease, $n(\%)$ & $56(44.4)$ \\
\hline Chronic total occlusion, $n(\%)$ & $20(15.9)$ \\
\hline Complete revascularization, $n(\%)$ & $98(77.8)$ \\
\hline \multicolumn{2}{|c|}{ Stenting technique for bifurcation disease, $n(\%)$} \\
\hline Crossing over LCX or LAD & $41(48.8)$ \\
\hline T stenting & $25(29.8)$ \\
\hline Collute stenting & $10(11.9)$ \\
\hline Crush technique & $8(9.5)$ \\
\hline Final kissing balloon, $n(\%)$ & $52(61.9)$ \\
\hline \multicolumn{2}{|l|}{ Stent type, $n(\%)$} \\
\hline Cypher & $87(69.0)$ \\
\hline Firebird & $26(20.6)$ \\
\hline Partner & $11(8.7)$ \\
\hline Excel & $2(1.6)$ \\
\hline No. of stents at left main per patient, $n$ & $1.4 \pm 0.5$ \\
\hline Mean stent diameter, mm & $3.4 \pm 0.4$ \\
\hline Total stents length, mm & $23.9 \pm 11.7$ \\
\hline
\end{tabular}

IMA indicates internal mammary artery; LAD, left anterior descending artery; and LCX, left circumflex artery. Other abbreviations as in Table I.
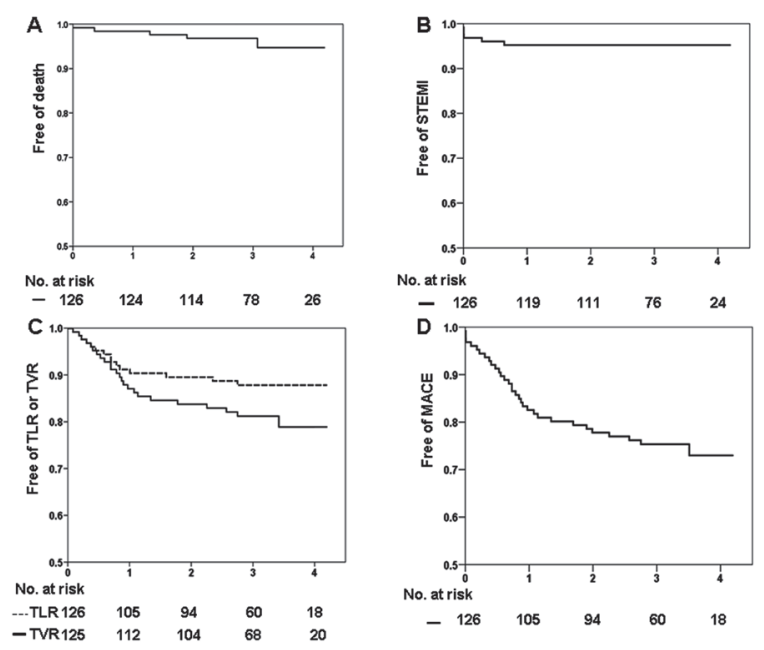

Figure. The freedom from death (A), TLR and TVR (B), STEMI (C), and MACE (D) survival curves during the entire follow-up constructed using Cox regression analysis. CABG indicates coronary artery bypass graft; STEMI, ST-segment elevation myocardial infarction; MACE, major adverse coronary events; PCI, percutaneous coronary intervention; TLR, target lesion revascularization; and TVR, target vessel revascularization.

and 6 occurred in patients with single stent $(20.9 \%$ versus $7.2 \%, P=0.04)$. The incidence of TLR was not different between the patients with versus without left main bifurcation disease $(14.3 \%$ versus $7.1 \%, P=0.382)$.

Multivariable analyses: The results of multivariable analyses are presented in Table IV. Of note, age and left main bifurcation 
Table III. Major Adverse Cardiac Events During Follow-Up

\begin{tabular}{|c|c|c|c|c|c|c|c|}
\hline $\begin{array}{c}\text { Events, } \\
n(\%)\end{array}$ & Overall & $\begin{array}{l}\text { Hospitali- } \\
\text { zation }\end{array}$ & $\begin{array}{c}\text { Discharge } \\
\text { to } \\
6 \text { months }\end{array}$ & $\begin{array}{c}6 \text { months } \\
\text { to } \\
1 \text { year }\end{array}$ & $\begin{array}{l}1 \text { year } \\
\text { to } \\
2 \text { years }\end{array}$ & $\begin{array}{l}2 \text { years } \\
\text { to } \\
3 \text { years }\end{array}$ & $\begin{array}{c}\text { After } \\
3 \text { years }\end{array}$ \\
\hline Death & $5(4.0)$ & $1(0.8)$ & 0 & $1(0.8)$ & $2(1.6)$ & 0 & $1(0.8)$ \\
\hline STEMI & $6(4.8)$ & $4(3.2)$ & 0 & $2(1.6)$ & 0 & 0 & 0 \\
\hline TLR & 15 (11.9) & 0 & $5(4.0)$ & $6(4.8)$ & $2(1.6)$ & $2(1.6)$ & 0 \\
\hline TVR & $25(19.0)$ & 0 & $6(4.8)$ & $9(7.1)$ & $4(3.2)$ & $4(3.2)$ & $1(0.8)$ \\
\hline MACE & $32(25.4)$ & $4(3.2)$ & $6(4.8)$ & $11(8.7)$ & $6(4.8)$ & $4(3.2)$ & $1(0.8)$ \\
\hline
\end{tabular}

MACE indicates major adverse cardiac events; STEMI, ST segment elevation myocardial infarction; TLR, target lesion revascularization; and TVR, target vessel revascularization.

Table IV. Multivariable Predictors of Freedom From Adverse Clinical Events

\begin{tabular}{lcccccc}
\hline \multirow{2}{*}{ Variable } & \multicolumn{2}{c}{ Death } & \multicolumn{2}{c}{ TLR } & \multicolumn{2}{c}{ MACE } \\
\cline { 2 - 7 } & HR $(95 \%$ CI $)$ & $P$ & HR $(95 \%$ CI $)$ & $P$ & HR $(95 \%$ CI $)$ & $P$ \\
\hline $\begin{array}{l}\text { Age } \\
\text { LVEF } \leq 40 \%\end{array}$ & $2.91(1.27,6.67)$ & 0.01 & $0.97(0.94,0.99)$ & 0.034 & - & - \\
$\begin{array}{l}\text { Bifurcation } \\
\text { disease }\end{array}$ & - & - & $2.22(1.04,4.76)$ & 0.04 & - & - \\
Euroscore $>6$ & $4.98(1.89,13.1)$ & 0.001 & - & - & $4.75(2.07,10.9)$ & $<0.001$ \\
\hline
\end{tabular}

Only significant $(P<0.05)$ predictors are reported, as hazard ratios $(95 \%$ confidence intervals $), P$ values. LVEF indicates left ventricular ejection fraction; MACE, major adverse cardiac event; and TLR, target lesion revascularization.

disease predicted the need for TLR; the impaired LVEF $(\leq 40 \%)$ and high surgical risk (Euroscore $>6$ ) were significant predictors of death and MACE.

\section{Discussion}

The major findings of this single-center, observational study are: 1) PCI with SES in ULMCA is feasible in a variety of lesions and has high clinical and procedural success rates. 2) During the nearly 4-year follow-up, there were comparatively low incidences of cardiac death (4.0\%), of a need for TLR (11.9\%) and TVR (19.0\%), and MACE (25.4\%). 3) In terms of safety, there were only $2(1.6 \%)$ cases of probable or possible stent thrombosis. 4) The independent predictors of death and MACE were LVEF $\leq 40 \%$ and Euroscore $>6$.

Although DES has been shown to be procedurally feasible for ULMCA stenosis, there is limited information on longterm outcomes. Recent advances in technology, devices, and operator experience, as well as antiplatelet therapy, have led to a steady expansion in the role of PCI in the treatment of ULMCA. Clinical outcomes after treatment of ULMCA disease with either an SES or paclitaxel-eluting stent from several small registries have been published. The results reported in these registries vary widely. ${ }^{21-26)}$ Cardiac mortality between 6 and 12 months after the procedure ranges from $0 \%$ to $11 \%$. The TLR or TVR rates ranged from $2 \%$ to $38 \%$. This variability most likely represented relative differences in patient selection and a lack of long-term follow-up results. Along with the other investigators, we observed a favorable outcome in the overall patients involving more than $20 \%$ of patients with a high surgical risk. Our results emphasize that the great majori- ty of adverse events occurred within the first year, whereas thereafter, the event rate tended to stabilize over time.

Despite encouraging results, restonosis is still a challenging issue in ULMCA disease. In the randomized SYNTAX (SYNergy Between PCI With TAXUS and Cardiac Surgery) trial, 12-month TVR rates reached $13.5 \%$ in the PCI group versus $5.9 \%$ in the CABG group. ${ }^{27)}$ The COMPARE registry also showed that DES was associated with higher rates of TLR $(9.7 \%$ versus $1.6 \%){ }^{28)}$ Lee, et al reported a cumulative incidence of TVR after 1 and 3 years of $18.8 \%$ and $20.7 \%$, respectively. ${ }^{29)}$ In the present study, SES was still associated with a relatively high TVR rate of $19.0 \%$. Notably, the high rate of TVR was also driven by a comparatively high rate of angiographic follow-up. Nearly a quarter of the patients (31/126) presented ACS and an ischemic-driven TVR was performed in over 20\% (26/126) of cases, which suggested that restenosis is not a benign entity even in ULMCA disease.

Initial reports warned of the potential risk of sudden death associated with ULMCA patients. However, according to the ARC definition of in-stent thrombosis, the incidence of probable and possible SES thrombosis at 4 years was only $1.6 \%$, likely because of the large diameter of the LM and frequent dual or triple antiplatelet therapy for a minimum of 1 year. A recent study suggested that cilostazol could ameliorate platelet responsiveness to clopidogrel in patients who underwent primary PCI. ${ }^{30)}$ Furthermore, some other studies showed that the administration of cilostazol after PCI could significantly lower the incidence of in-stent restenosis. ${ }^{31-34)}$ The significant morbidity and mortality benefits of low-dose aspirin and angiotensinconverting enzyme inhibitors in coronary artery disease are also worthy of consideration.

The fact that there were predictors of long-term success 
may help the selection of the most appropriate patient for DES treatment of ULMCA. The Euroscore might be a marker of severe morbidity and, as such, carry with it a worse prognosis irrespective of the final revascularization strategy. A preserved left ventricular function is one of the most important parameters to be considered.

Study limitations: The main limitation of this study was this series represents a retrospective selected group of patients with ULMCA disease. The relatively small study population is another important limitation. In addition, scheduled angiographic follow-up was still less rigorous in asymptomatic patients.

Conclusions: During nearly 4-years of follow-up, in this single-center, retrospective experience, patients with ULMCA disease treated with SES demonstrated relatively lower rates of death and MACE, whereas SES was associated with a relatively higher rate of TLR and TVR. Impaired LVEF and high surgical risk were important predictors of MACEs.

\section{REFERENCES}

1. Johnson LW, Lozner EC, Johnson S, et al. Coronary arteriography 1984-1987: a report of the Registry of the Society for Cardiac Angiography and Interventions. I. Results and complications. Cathet Cardiovasc Diagn 1989; 17: 5-10.

2. Ragosta M, Dee S, Sarembock IJ, Lipson LC, Gimple LW, Powers ER. Prevalence of unfavorable angiographic characteristics for percutaneous intervention in patients with unprotected left main coronary artery disease. Catheter Cardiovasc Interv 2006; 68: 35762.

3. Valgimigli M, van Mieghem CA, Ong AT, et al. Short- and longterm clinical outcome after drug-eluting stent implantation for the percutaneous treatment of left main coronary artery disease: insights from the Rapamycin-Eluting and Taxus Stent Evaluated At Rotterdam Cardiology Hospital registries (RESEARCH and TSEARCH). Circulation 2005; 111: 1383-9.

4. Price MJ, Cristea E, Sawhney N, et al. Serial angiographic followup of sirolimus-eluting stents for unprotected left main coronary artery revascularization. J Am Coll Cardiol 2006; 47: 871-7.

5. Chieffo A, Stankovic G, Bonizzoni E, et al. Early and mid-term results of drug-eluting stent implantation in unprotected left main. Circulation 2005; 111: 791-5.

6. Park SJ, Kim YH, Lee BK, et al. Sirolimus-eluting stent implantation for unprotected left main coronary artery stenosis: comparison with bare metal stent implantation. J Am Coll Cardiol 2005; 45 351-6.

7. Chieffo A, Morici N, Maisano F, et al. Percutaneous treatment with drug-eluting stent implantation versus bypass surgery for unprotected left main stenosis: a single-center experience. Circulation 2006; 113: 2542-7.

8. Christiansen EH, Lassen JF, Andersen HR, et al. Outcome of unprotected left main percutaneous coronary intervention in surgical low-risk, surgical high-risk, and acute myocardial infarction patients. EuroIntervention 2006; 1: 403-8.

9. Lee MS, Kapoor N, Jamal F, et al. Comparison of coronary artery bypass surgery with percutaneous coronary intervention with drug-eluting stents for unprotected left main coronary artery disease. J Am Coll Cardiol 2006; 47: 864-70.

10. Colombo A, Orlic D, Stankovic G, et al. Preliminary observations regarding angiographic pattern of restenosis after rapamycin-eluting stent implantation. Circulation 2003; 107: 2178-80.

11. Moses JW, Leon MB, Popma JJ, et al. Sirolimus-eluting stents versus standard stents in patients with stenosis in a native coronary artery. N Engl J Med 2003; 349: 1315-23.

12. Park SJ, Lee CW, Kim YH, et al. Technical feasibility, safety, and clinical outcome of stenting of unprotected left main coronary artery bifurcation narrowing. Am J Cardiol 2002; 90: 374-8.
13. Colombo A, Stankovic G, Orlic D, et al. Modified T-stenting technique with crushing for bifurcation lesions: immediate results and 30-day outcome. Catheter Cardiovasc Interv 2003; 60: 145-51.

14. Nashef SA, Roques F, Michel P, Gauducheau E, Lemeshow S, Salamon R. European system for cardiac operative risk evaluation (EuroSCORE). Eur J Cardiothorac Surg 1999; 16: 9-13.

15. Parsonnet V, Dean D, Bernstein AD. A method of uniform stratification of risk for evaluating the results of surgery in acquired adult heart disease. Circulation 1989; 79: I3-12.

16. Du R, Zhang RY, Zhu ZB, et al. Intravascular ultrasound evaluation on the efficacy of national made Firebird stents comparing with Cypher stents. Zhonghua Xin Xue Guan Bing Za Zhi 2010; 38: 121-5. (Chinese)

17. Zhang YX, Lu CY, Xue Q, et al. Safety and efficacy comparison between rapamycin-eluting stent with biodegradable polymer or permanent polymer in patients with coronary artery disease. Zhonghua Xin Xue Guan Bing Za Zhi 2006; 34: 971-4. (Chinese)

18. Han $\mathrm{Y}$, Jing $\mathrm{Q}$, Chen $\mathrm{X}$, et al. Long-term clinical angiographic, and intravascular ultrasound outcomes of biodegradable polymercoated sirolimus-eluting stents. Catheter Cardiovasc Interv 2008; 72: $177-83$.

19. Liu HB, Xu B, Yang YJ, et al. Long-term clinical outcomes after bioabsorbable polymer- and durable polymer-based sirolimuseluting stents implantation: two-year follow-up results from a large single-center database. Chin Med J (Engl) 2009; 122: 681-6.

20. Cutlip DE, Windecker S, Mehran R, et al. Clinical end points in coronary stent trials: a case for standardized definitions. Circulation 2007; 115: 2344-51.

21. Han YL, Wang SL, Jin QM, et al. Efficacy of stenting for unprotected left main coronary artery disease in 297 patients. Chin Med J (Engl) 2006; 119: 544-50.

22. Erglis A, Narbute I, Kumsars I, et al. A randomized comparison of paclitaxel-eluting stents versus bare-metal stents for treatment of unprotected left main coronary artery stenosis. J Am Coll Cardiol 2007; 50: 491-7.

23. Colombo A, Moses JW, Morice MC, et al. Randomized study to evaluate sirolimus-eluting stents implanted at coronary bifurcation lesions. Circulation 2004; 109: 1244-9.

24. Meliga E, Garcia-Garcia HM, Valgimigli M, et al. Longest available clinical outcomes after drug-eluting stent implantation for unprotected left main coronary artery disease: the DELFT (Drug Eluting stent for LeFT main) Registry. J Am Coll Cardiol 2008; 51: 2212-9.

25. Mehilli J, Kastrati A, Byrne RA, et al. Paclitaxel- versus sirolimuseluting stents for unprotected left main coronary artery disease. J Am Coll Cardiol 2009; 53: 1760-8.

26. Sheiban I, Meliga E, Moretti C, et al. Long-term clinical and angiographic outcomes of treatment of unprotected left main coronary artery stenosis with sirolimus-eluting stents. Am J Cardiol 2007; 100: $431-5$

27. Serruys PW, Morice MC, Kappetein AP, et al. Percutaneous coronary intervention versus coronary-artery bypass grafting for severe coronary artery disease. N Engl J Med 2009; 360: 961-72.

28. Seung KB, Park DW, Kim YH, et al. Stents versus coronary-artery bypass grafting for left main coronary artery disease. N Engl J Med 2008; 358: 1781-92.

29. Lee BK, Hong MK, Lee CW, et al. Five-year outcomes after stenting of unprotected left main coronary artery stenosis in patients with normal left ventricular function. Int J Cardiol 2007; 115: 20813.

30. Kim JY, Lee K, Shin M, et al. Cilostazol could ameliorate platelet responsiveness to clopidogrel in patients undergoing primary percutaneous coronary intervention. Circ J 2007; 71: 1867-72.

31. Tsuchikane E, Fukuhara A, Kobayashi T, et al. Impact of cilostazol on restenosis after percutaneous coronary balloon angioplasty. Circulation 1999; 100: 21-6.

32. Douglas JS Jr, Holmes DR Jr, Kereiakes DJ, et al. Coronary stent restenosis in patients treated with cilostazol. Circulation 2005; 112: 2826-32.

33. Min PK, Jung JH, Ko YG, Choi D, Jang Y, Shim WH. Effect of 
cilostazol on in-stent neointimal hyperplasia after coronary artery stenting: a quantitative coronary angiography and volumetric intravascular ultrasound study. Circ J 2007; 71: 1685-90.

34. Lee SW, Park SW, Kim YH, et al. Drug-eluting stenting followed by cilostazol treatment reduces late restenosis in patients with dia- betes mellitus the DECLARE-DIABETES Trial (A Randomized Comparison of Triple Antiplatelet Therapy with Dual Antiplatelet Therapy After Drug-Eluting Stent Implantation in Diabetic Patients). J Am Coll Cardiol 2008; 51: 1181-7. 